\title{
Fish Output and Food Security under Risk Management Strategies among Women Aquaculture Farmers in Ondo State, Nigeria
}

Lawrence Olusola Oparinde

Department of Agricultural and Resource Economics, Federal University of Technology, Akure, Nigeria

\begin{abstract}
This study examined the impact of risk management strategies' adoption on fish output and food security among women aquaculture farmers in Ondo State, Nigeria. Multistage sampling procedure was used to select 90 respondents. Endogenous switching regression model and recursive bivariate probit model were employed to carry out the impact analysis. The empirical findings revealed that farmer's age, household size, education, non-farm income, pond system, quantity of feed, credit constraint, and risk attitude significantly influenced risk management strategies' adoption. Moreover, adoption of risk management strategies increased fish output and reduced food insecurity among women aquaculture farmers. In conclusion, adoption of risk management strategies is capable of enhancing fish output and reducing food insecurity. Therefore, development agents should encourage women aquaculture farmers to adopt risk management strategies in order to have increased fish output and reduced food insecurity which can help in bridging fish supply-demand gap and reducing their level of vulnerability.
\end{abstract}

\section{Keywords}

Risk management, women, aquaculture farmers, fish, food security.

Oparinde, L. O. (2019) "Fish Output and Food Security under Risk Management Strategies among Women Aquaculture Farmers in Ondo State, Nigeria", AGRIS on-line Papers in Economics and Informatics, Vol. 11, No. 1, pp. 93-105. ISSN 1804-1930. DOI 10.7160/aol.2019.110110.

\section{Introduction}

Hecht (2006) stated that the contributions of aquaculture to livelihoods, national economic development and food security in Africa are very important. There is total or partial dependence of between 660 and 820 million people on fisheries, aquaculture and related industries as a source of income (HLPE, 2014). There is no any other food producing sector that grows faster than aquaculture and capture fisheries production in response to global demand will be augmented by aquaculture if the growth is sustained (Bostock et al. 2010). However, it faces series of risks higher than the crops considering its complexity in terms of species, environments and systems (Forum for Agricultural Risk Management Development (FARMD) 2017). This is supported by Ahsan and Roth (2010) who explained that aquaculture, like any other agri-businesses, is a risky business with production risk as one of the types of risk associated with it.

Records of Federal Department of Fisheries (FDF) and Food and Agriculture Organisation (FAO) revealed that Nigeria was recording self- sufficiency ratio of $98.8 \%$ in 1983 and later reduced to $40 \%$ and $19.2 \%$ in 2005 and 2014 respectively with average of about $49 \%$ per annually (Oladimeji, 2017). FAO (2013) indicated that Nigeria has been importing over US\$400 million fish annually because fish demand in Nigeria has not been met.

Biotic and abiotic processes that cannot be totally understood affect agricultural production. There may be little that can be done to control the processes even if there is a reasonable understanding of such processes (Hurley, 2010). Ogundari and Akinbogun (2010) stated that since some inputs have increasing or decreasing effect on level of production risk, Tveterås (1999) therefore, emphasized that consideration should be given to production risk in inputs in the empirical analysis of productivity change. This is important since majority of the key risks in agriculture have close relations with or direct consequences on food security (FAO, 2016).

Food security exists when all people, at all times, have physical and economic access to sufficient, safe and nutritious food that meets their dietary needs and food preferences for an active and healthy 
life (World Food Summit, 1996). Food security is a great concern in Nigeria going by its position in the food security index as the 2017 Global Food Security Index ranked Nigeria $92^{\text {nd }}$ out of 113 countries (The Economist Group, 2017). Garcia and Rosenberg (2010) stated that fisheries can contribute to food security directly and indirectly. It is directly in the sense that fisheries can serve as a source of essential nutrients and indirectly as a source of income to buy food. Managing risk is an important aspect of reducing food insecurity, protecting livelihoods and opening up investment opportunities and income growth since it is clear that risk is an unavoidable part of economic and social activities in agriculture (Kassie et al., 2015). Risk management methods provide means to address increasing complexity for successful agriculture management (such as fisheries management) by systematically identifying and coping with risk (Sethi, 2010). It involves choosing among alternatives to reduce the effects of risks (Harwood et al., 1999).

There are various studies on how the use of inputs and technologies affect production risk in agriculture (such as Ogundari and Akinbogun, 2010). Also, there is a long established literature on risk management strategies used by aquaculture farmers. With these in the literature, there is little or no information about how risk management strategies affect fish output and food security especially among women aquaculture farmers being the most vulnerable group. Moreover, studies on how combinations of risk management strategies impact fish output and food security among women aquaculture farmers are still lacking in the literature. In order to increase fish output in the presence of risk, multiple risk management strategies are employed by the farmers as compliments. Hence, this study examined the impact of risk management strategies' adoption on fish output and food security among women aquaculture farmers in Ondo State, Nigeria.

This paper contributes to the body of knowledge in the following ways. This study has considered the importance of synergetic effects of risk management strategies combinations in the attainment of increased fish output and food security. Second, the impact of risk management strategies' adoption on fish output and food security among women aquaculture farmers being the most vulnerable is examined. Lastly, in order to simultaneously estimate the determinants and impact of risk management strategies adoption, while accounting for both observable and unobservable factors in an efficient manner, endogenous switching regression model approach (Lokshin and Sajaia, 2004) was used for output being a continuous outcome. In the case of food security being a binary outcome, a recursive bivariate probit model was used (Joshi et al., 2015). Risk management strategies considered in this study are financial liquidity reservation (savings), membership of professional association (such as Cooperative societies) and following required standard in the establishment of fish farm. Any farmer who did not practice any of the three risk management strategies is regarded as non-adopter, while any farmer who practiced one or more of the risk management strategies is termed adopter.

\section{Materials and methods}

\section{Study area}

The study was carried out in Ondo State, Southwest Nigeria. The State lies between longitudes $4^{\circ} 30^{11}$ and $6^{11}$ East of the Greenwich Meridian, $5^{\circ} 45^{11}$ and $8^{\circ} 15^{11}$ North of the Equator. The State has a land area of about 14,793 square kilometers $\left(\mathrm{km}^{2}\right)$ (Ondo State Government, 2016) and its population is about 3,460,877 (National Bureau of Statistics (NBS), 2011). Some of the inhabitants of the State are fish farmers while most of them cultivate food crops such as cocoyam, sweet potato, tomato, maize, pepper, plantain and cash crops such as cocoa and timber are cultivated in the state (Oseni, 2010).

\section{Data collection and sampling procedure}

Primary data were collected through administration of well-structured questionnaire and interview schedule on the selected respondents. Multistage sampling procedure was used to select the respondents. In the first stage, simple random sampling technique was used to select 9 Local Government Areas in the State. In the second stage, five (5) communities were purposively selected considering the level of urbanization from each of the selected Local Government Areas. In the third stage, two (2) women aquaculture farmers were selected using snow ball sampling technique from each of the selected communities. In all, a total of 90 respondents were selected for the study.

\section{Data analytical procedure}

Descriptive Statistics, Endogenous Switching Regression Model and Recursive Bivariate Probit Model were used for the analysis of data. Out of 90 copies of questionnaire administered, 87 copies were used for the analysis. The remaining 
3 were not used due to insufficient data provided. Household expenditure on food has been widely used by various researchers (such as FAO, 2003; Adepoju and Adejare, 2013) in estimating food security line for rural households. It is on this basis that two-third of the mean per capita monthly food expenditure of all the households was used to estimate the food security line. Household is said to be food secure if its per capita monthly food expenditure is equal to or above the twothird mean-per capita monthly food expenditure, while food insecure household is the one with percapita monthly food expenditure of less than twothird mean-per capita monthly food expenditure. In this study, 1 is assigned to household that is food insecure, while the household that is food secure is assigned 0 .

\section{Household impact evaluation and selection bias}

It is assumed that women fish farmers are risk neutral, evaluate benefits associated with adoption and non-adoption of risk management strategies, denoted by $S_{i A}$ and $S_{i N}$ respectively. Another assumption is that only the adoption status is known to the researcher, while the household net benefits and other preferences are known to the women fish farmer only. Unobserved net benefits of the fish farmer $i$ is denoted by $S_{i}^{*}=S_{i A}-S_{i N}$. The basic relationship used here is that net benefit from risk management strategies' adoption is expressed with respect to a vector of household explanatory variables $\left(X_{i}\right)$ in a latent variable framework. The relationship is expressed as follows;

$S_{i}^{*}=X_{i}^{\prime} \alpha+\varepsilon_{i}, S_{i}=1\left[S_{i}^{*}>0\right]$,

where $S_{i}$ is a dichotomous variable with $1=$ farmers who did not adopt and $0=$ who adopted, $X$ represents all observable factors that influence adoption of risk management strategies, $\alpha$ is a vector of parameters to be estimated, $\varepsilon$ is the error term with mean zero, and variance $\sigma_{\varepsilon}^{2}$ which captures measurement errors and unobserved factors.

Given that the primary aim of this study is to analyse the impact of risk management strategies' adoption on fish output and food security among women aquaculture farmers, a framework that captures the farmers' choice of adoption is applied. The relationship being considered in examining the effect of risk management strategies' adoption on farmers' fish output and food security assumes that vector of outcome variables is a linear function of a vector of explanatory variables $\left(X_{i}\right)$ and risk management strategies' adoption which is a dichotomous variable $\left(S_{i}\right)$. The relationship can be expressed as follows;

$Y_{i}=K_{i}^{\prime} \beta+S_{i}+\mu_{i}$

where variable $Y_{i}$ is a vector of outcome variables, $K_{i}$ is a vector of farm and household characteristics, $S_{i}$ is the adoption status, $\mu_{i}$ is a random error term while $\beta$ and $\gamma$ are vector of parameters to be estimated.

According to Abdulai (2016), selection bias ensues if error terms of the outcome equation, $(\mu)$ and choice equation $(\varepsilon)$ are influenced by unobservable factors. Therefore, correlation of the error terms of the outcome and choice equations will come into play and ordinary least square will give biased estimates. As explained by Asfaw et al. (2012) the selection bias problem is addressed by randomly allocating individuals into treatment and control groups in a randomized control trial set up.

However, this case is not the same in a nonrandomized experimental set up like adoption of risk management strategies which is not random and selection bias may come up. Authors such as Nkala et al, (2011) have employed Propensity Score-Matching (PSM) Approach in impact evaluation of technology on household welfare when there is self-selection. Nevertheless, Abdulai (2016) has stated that PSM approach has its own major drawback of only accounting for the observable factors. In order to simultaneously estimate the determinants and impact of adoption as well as account for observable and unobservable factors in an efficient manner, an Endogenous Switching Regression (ESR) model approach which was developed by Lokshin and Sajaia (2004) is used. It is worthy of note that ESR is suitable for expected outcome that is continuous in nature such as fish output but impact evaluation of adoption on food security, which is a dichotomous outcome variable needs a different specification. Seemingly unrelated regression approach cannot be used since adoption and food security status are dichotomous dependent variables. Therefore, Recursive Bivariate Probit (RBP) model is used to estimate the adoption and impact of risk management strategies on food security status because it accounts for endogeneity and selection bias.

\section{Empirical specifications}

Endogenous Switching Regression (ESR) model In the process of modeling the impact of risk 
management strategies' adoption on the fish output using ESR framework, a two-stage estimation procedure is simultaneously estimated. In the first stage, the adoption decision in equation (1) is estimated in order to determine the factors that influence adoption. The second stage involves the estimation of relationship between the outcome variables and a set of explanatory variables specified for two regimes of adopters and non-adopters of risk management strategies. The specifications for the two regimes are as follows;

Regime 1(Adopters): $Y_{i A}=K_{i A} \beta+\mu_{i A}$ if $S_{i}=0$ (3a)

Regime 2 (Non-adopters): if $S_{i}=1$

where $Y_{i A}$ and $Y_{i N}$ are outcome variables for adopters and non-adopters, respectively; $K$ is a vector of household and farm-level characteristics; $\beta$ is a vector of parameters to be estimated and $\mu$ is the error term. The structure of the ESR model allows for an overlap of $X$ in Equation (1) and $K$ of Equations (3a) and (3b). However, it is important that at least one variable does not appear in $K$ for the purpose of identification. Therefore, this implies that the same set of variables are used to estimate selection and outcome equation but with additional one variable in the former. Awareness about risk management strategies is used as a valid instrument as it is expected to influence adoption decision and not the outcome. Only observable factors are accounted for in equations $3 \mathrm{a}$ and $3 \mathrm{~b}$ by variables in $\mathrm{K}$. But it is possible for ESR model to address the selection bias problem owing to unobservable factors within the structure of omitted variable problem. As explained by Heckman (1979), the selectivity terms used in the selection equation which represent $\lambda_{A}$ and $\lambda_{N}$ for adopters and non-adopters, respectively, covariance terms $\sigma_{A N}$ and $\sigma_{A \varepsilon}$ are included in equation $3 \mathrm{a}$ and $3 \mathrm{~b}$ which resulted to equation $4 \mathrm{a}$ and $4 \mathrm{~b}$ below;

$Y_{i A}=K_{i A} \beta+\sigma_{A \varepsilon} \lambda_{A}+\varphi_{i A}$ if $S_{i}=0$

$Y i N=K_{i N} \beta+\sigma_{N \varepsilon} \lambda_{N}+\varphi_{i N} \quad$ if $\quad S_{i}=1$

where the selectivity terms $\lambda_{A}$ and $\lambda_{N}$ correct for selection bias from unobservable factors and $\varphi_{i A}$ and are the error terms with conditional zero means. Maximum likelihood approach was used in this study as proposed by Lokshin and Sajaia (2004) and used by Abdulai (2016). The ESR model is used to examine the impact of adopting risk management strategies on fish output by comparing the expected fish output of farmers who adopt with expected outcomes of the counterfactual hypothetical cases that adopters did not adopt. The expected values of the outcome $Y$ on adoption and non-adoption can be expressed as follows;

$$
\begin{aligned}
& E\left(Y_{i A} \mid S=1\right)=K^{\prime} \beta_{i A}-\sigma_{A \varepsilon} \lambda_{A} \\
& E\left(Y_{i N} \mid S=1\right)=K^{\prime} \beta_{i N}-\sigma_{N \varepsilon} \lambda_{A}
\end{aligned}
$$

According to Lokshin and Sajaia (2004), average treatment effect on the treated (ATT) is a change in the outcome due to adoption, which is expressed as follows in equation 6 as the difference in the expected outcomes from equations $5 \mathrm{a}$ and $5 \mathrm{~b}$.

$$
\begin{aligned}
& A T T=E(Y i A \mid S=1)-E\left(Y_{i N} \mid S=1\right) \\
& A T T=K(\beta i A-\beta i N)+\lambda A(\sigma A \varepsilon-\sigma N \varepsilon)
\end{aligned}
$$

where $\sigma$ represents the covariance of the error terms and $\lambda$ the inverse mills ratios or selectivity term.

\section{Recursive Bivariate Probit (PBP) model}

Awotide et al. (2013); Kuntashula et al. (2014) have used Heckman two-stage selection method to evaluate impact of a dichotomous variable on a dichotomous outcome. The method was used to account for observed and unobserved heterogeneity between adopters and non-adopters. However, Lokshin and Sajaia (2004) argued that heteroskedastic residuals are generated by two-stage approach, which cannot be used to obtain consistent standard errors without cumbersome adjustments. Therefore, this study employs RBP model to jointly estimate adoption of risk management strategies and its impact on dichotomous variable (such as food security) in order to overcome the shortcoming as used by (Amare et al., 2012 and Abdulai, 2016). The selection equation described in equation 1 is equally needed in RBP model so as to take care of possibly endogenous binary variable and outcome equation described in equation 2. The model is expressed as follows;

$S_{h}^{*}=X_{h}^{\prime} \theta+\varepsilon_{h^{\prime}}, S_{i}=1\left[S_{i}^{*}>0\right]$

$Y_{h}=K_{h}^{\prime}+S_{h}{ }^{\prime} \omega+\mu_{h}$

where variable $S_{h}{ }^{*}$ is the latent adoption outcome of the farming household; $X_{h}$ includes all factors influencing risk management strategies' adoption decision, such as household and farmlevel characteristics; $Y_{h}$ represents food security status for household; $K_{h}$ is a vector of household and farm-level characteristics (e.g., age, education); $S_{h}$ indicates farmers' adoption status; $\mu_{h}$ and $\varepsilon_{h}$ are random error terms which are assumed to follow a bivariate distribution; $\theta$ and $\phi$, and $\omega$ are 
parameters to be estimated. Following Marra and Radice (2011), the assumption that the error terms follow a bivariate distribution is expressed as follows;

$$
\left(\left[\begin{array}{ll}
1 & \rho \\
\rho & 1
\end{array}\right]\right)
$$

where $\rho$ represents correlation coefficient among unobserved explanatory variables in both equations.

For the purpose of identification as it is in ESR model, it is vital to make sure that the exclusion restriction on the exogenous variables hold, that is $X_{h}$ and $K_{h}$ must be different by the minimum of a variable (Maddala, 1983). The bivariate normal cumulative distribution function is specified in equation 10 and if $\rho$ is significant, it indicates that correlation of disturbance terms exists.

$$
Я\left(X_{k}, K_{k}, \rho\right)=\frac{e^{-1 / 2\left(X_{h}^{2}+K_{h}^{2}-2 \rho X_{h} K_{h}\right) /\left(1-\rho^{2}\right)}}{2 \pi\left(1-\rho^{2}\right)^{1 / 2}}
$$

The nonlinear conditional expectation expressed in equation 11 is meant to estimate the marginal effects, while the average treatment effect on the treated (ATT) is estimated using equation 12 .

$$
\begin{aligned}
& E\left[s_{h} \mid Y_{h}, K_{h}\right]=\frac{g\left(\emptyset X_{h},\left(2 Y_{h}-1\right) \emptyset K_{h},(2 Y-1) \rho\right)}{Я\left[\left(2 Y_{h}-1\right) \emptyset K_{h}\right]} \\
& A T T=E\left(Y_{h A} \mid S=1\right)-E\left(Y_{h N} \mid S=1\right)
\end{aligned}
$$

where $Y_{h A}$ is the expected probability of food security status from adoption, and is the expected probability of food security outcome in the counterfactual case.

Credit constraint and adoption decision may be jointly determined and this is capable of causing potential endogeneity problems in Endogenous Switching Regression Model and Recursive Bivariate Probit Model estimation. There may be bias estimates if such potential endogeneity problems are not accounted for. In view of this, the endogeneity issue is accounted for using two-stage procedure of Blundell and Smith (1989) since the dependent variable is dichotomous. The first stage involved the specification of potentially endogenous variable (credit constraint) as a function of all other independent variables including a set of instruments as in equation 13 .

$\operatorname{Pr}\left[V_{i}=1\right]=\aleph^{\prime} G_{i}+\tau^{\prime} T_{i}+e$

where $V_{i}$ is a vector of the potential endogenous variables, $G_{i}$ is a vector of independent variables, while $T_{i}$ is a vector of instruments that are correlated with the given endogenous variable, but uncorrelated with the error terms in equation 13. A variable that influences credit constraint but does not influence the outcome variables was included in equation 13 for identification purpose. Possession of collateral which influences credit constraint but not the outcome variable was used as an instrument in the credit constraint specification. However, the second stage involved the inclusion of the values of credit constraint as well as their corresponding residuals from equation 13 in ESR model. Therefore, consistent estimation of the parameters in the presence of potential endogenous variable in $T_{i}$ is possible. A simple t-test for the significance of the coefficient vector is a test for the exogeneity of these variables (Wooldridge, 2010).

\section{Results and discussion}

\section{Summary of statistics}

Table 1 presents the variable names, descriptive statistics of adopters and non-adopters. The t-test values indicating the differences between women fish farmers who adopted risk management strategies and those who did not adopt suggest that there are statistically significant differences between the two groups with respect to some household and farm level characteristics. For instance, women fish farmers who adopted risk management strategies obtained $1,420.3 \mathrm{~kg}$ of fish output, while those who did not adopt the risk management strategies realized $1,278.1 \mathrm{~kg}$ of fish output. Also, there is a significant difference between the age of adopters and non-adopters with 52.03years and 40.57 years respectively. Furthermore, adopters spent about 16.53 years in school, while non-adopters spent about 10.52 years in school. Moreover, adopters and non-adopters differ significantly in household size, quantity of feed used, non-farm income, credit constraint, awareness about risk management strategies and risk attitude. About $49 \%$ of women fish farmers who adopted risk management strategies were food insecure, while $76 \%$ of those who did not adopt were food insecure. The reported differences for fish output and food security status in Table 1 could be interpreted as impacts, but this may not be absolutely correct since some other confounding factors are not taken into consideration. In view of this, this study gave serious consideration to other confounding factors in the analysis. 


\begin{tabular}{|c|c|c|c|c|}
\hline Variable & Variable description & Adopters & Non-adopters & Difference \\
\hline Household size & Household size of the respondents & 4.13 & 6.16 & $-2.03 *$ \\
\hline Experience & Experience of the respondents in years & 6.34 & 5.50 & 0.84 \\
\hline Marital status & Marital Status of the respondents & 0.21 & 0.23 & -0.02 \\
\hline Fish output & Quantity of fish harvested in $\mathrm{kg}$ & 1420.30 & 1278.10 & $142.2 .20 * * *$ \\
\hline Labour cost & Cost of labour used in Naira & $54,561.97$ & $53,613.07$ & 948.9 \\
\hline Pond system & 1 if farmer uses earthen pond and 0 otherwise & 0.52 & 0.76 & -0.24 \\
\hline Risk attitude & 1 if the farmer is risk seeking and 0 otherwise & 0.97 & 0.51 & $0.46^{* *}$ \\
\hline Awareness & $\begin{array}{l}1 \text { if the farmer is aware of risk management strategies, } 0 \\
\text { otherwise }\end{array}$ & 0.85 & 0.32 & $0.53 * *$ \\
\hline \multicolumn{2}{|c|}{ Number of observations } & 34 & 34 & \\
\hline
\end{tabular}

Note: $* * *$ and $* * *$ represent significance at $10 \%, 5 \%$ and $1 \%$ levels respectively

Source: own processing

Table 1: Variable names, descriptions and descriptive statistics of adopters and non- adopters.

\section{Relevant test results in the estimation strategy}

As shown in Tables 2 and 3, there are some relevant test results that have to be discussed before moving to the discussion of empirical estimates in this study. To start with, the estimates of credit constraint residual obtained from the first stage estimates of equation 13 are not statistically significant in the specifications used. This indicates that the coefficients of credit constraint variable have been consistently estimated (Wooldridge, 2010). Also, the likelihood ratio tests for joint independence of the equations in endogenous switching regression model and recursive bivariate probit regression model specifications revealed that the equations are dependent. The implication of this is that the models should not be estimated separately because they are not jointly independent. Another result indicates that there was an occurrence of selection bias in adoption since correlation coefficient $(\rho)$ in the specifications are significant. Therefore, it can be said that the use of endogenous switching regression (ESR) model and recursive bivariate probit model which account for both observable and unobservable factors are appropriate for this study (Lokshin and Sajaia, 2004).

The correlation coefficients $\rho_{1}$ and $\rho_{2}$ are both statistically significant. Since $\rho_{1}$ is positive and $\rho_{2}$ is negative, it implies that non-adopters had lower output and higher food insecurity than a random individual from the sample. However, adopters had higher output and lower food insecurity than a random individual from the sample. These results confirm Kassie et al., (2015) who stated that managing risk is an important aspect of reducing food insecurity, protecting livelihoods and opening up investment opportunities and income growth since it is clear that risk is an unavoidable part of economic and social activities in agriculture. Lastly, the log-likelihood ratio is significant at $1 \%$, which implies that the recursive bivariate regression model is overall a good fit.

\section{Determinants of adoption}

The results from the selection equation are presented in Tables 2 and 3 together due to the fact that the empirical results in the selection equation can be interpreted as normal probit coefficients. It is worthy of note that estimates for variables with the same name in the selection equation (probability of adopting risk management strategies) have similar effects on the dependent variable. As shown in the results, increase in age of the respondents tends to increase the probability of being non-adopter of risk management strategies in ESR and RBP models. This may be traced to their inability to cope with the laborious nature of risk management due to old age. The outcome of this study is in conformity with Ullah et al. (2015) who reported that increase in age reduced the adoption of risk management strategies.

Household size, level of education, non-farm income and quantity of feed had negative but significant 
relationship with adoption status. The implication of this scenario is that these variables increase the likelihood of adopting risk management strategies. The reason for this could be attributed to the fact that increase in level of education assists women fish farmers in the area of adoption of new technologies in spite of the associated risk since they know that risk always comes with great benefits, hence the need to adopt risk management strategies. This is in line with Olawuyi and Olawuyi (2015), who reported that number of years spent in school increased adoption of risk management strategies. Also, negative relationship between household size and adoption of risk management strategies may be due to the fact that some risk management strategies are laborious, which require more hands that can be gotten from household members. Saqib et al. (2016) reported that family size increases the probability of adopting risk management strategies.

The relationship that exists between non-farm income and risk management strategies' adoption could be linked to the importance of diversification of means of livelihood as one of the risk management strategies. Ullah and Shivakoti (2014) explained that off- farm income is capable of assisting farmers in investing on risk management options that can reduce other risks on the farm. Also, awareness about risk management strategies and risk attitude exhibit negative but significant relationship with adoption status, indicating that being aware about risk management strategies and risk seeking are likely to increase women fish farmers' chance of adopting risk management strategies across the two specifications. Ullah et al. (2015) reported a similar result which stated that risk perception and attitude of the farmers are important factors in farm risk management decisions. However, credit constraint and pond system are positive and significant in ESR and RBP models, which indicates that being credit constrained and using earthen pond system tend to reduce the probability of adopting risk management strategies. This result is in support of outcome of study by Deressa et al. (2010) who reported that access to credit will increase adoption of various risk management strategies.

\begin{tabular}{|c|c|c|c|c|c|c|}
\hline & \multicolumn{2}{|c|}{ Selection } & \multicolumn{2}{|c|}{ Adopters } & \multicolumn{2}{|c|}{ Non-adopters } \\
\hline & Coefficient & t-value & Coefficient & t-value & Coefficient & t-value \\
\hline Constant & 5.920 & 2.24 & 3.010 & 4.71 & 5.335 & 7.45 \\
\hline Age & $0.208^{* * *}$ & 2.76 & $0.421 * *$ & 2.01 & $0.314 *$ & 1.89 \\
\hline $\mathrm{Age}^{2}$ & -0.241 & 0.10 & -1.326 & 1.21 & -0.759 & 0.32 \\
\hline Household size & $-0.041 * * *$ & 9.62 & $0.736^{* *}$ & 2.11 & 0.114 & 1.43 \\
\hline Experience & 0.132 & 0.34 & 0.132 & 1.52 & 0.527 & 1.48 \\
\hline Marital status & 0.541 & 0.46 & 0.335 & 0.95 & 0.796 & 0.74 \\
\hline Education & $-0.134 * * *$ & 4.30 & $1.493 * *$ & 2.01 & $0.309^{* * *}$ & 4.47 \\
\hline Non-farm income & $-1.034^{* *}$ & 2.12 & $0.663 * * *$ & 4.21 & 0.759 & 1.34 \\
\hline Labour cost & -0.271 & 1.53 & 0.801 & 0.14 & -0.955 & 0.92 \\
\hline Credit constraint & $0.482 * * *$ & 3.72 & $-0.823 * *$ & 2.00 & $-0.612 *$ & 1.92 \\
\hline Pond system & $0.624 * * *$ & 7.23 & $-0.553 * * *$ & 3.10 & 0.321 & 1.13 \\
\hline Quantity of feed & $-0.575^{* *}$ & 2.11 & $0.421 * * *$ & 8.67 & 0.022 & 0.22 \\
\hline Risk attitude & $-0.544 * * *$ & 5.76 & 0.542 & 1.54 & $0.545^{* * *}$ & 4.22 \\
\hline Awareness & $-0.417 * * *$ & 2.95 & & & & \\
\hline Credit residual & 0.062 & 1.23 & & & & \\
\hline $\ln \sigma_{1}$ & & & $8.172 * * *$ & 13.19 & & \\
\hline$\rho_{1}$ & & & $0.161 * *$ & 2.15 & & \\
\hline $\ln \sigma_{2}$ & & & & & $4.253 * * *$ & 10.13 \\
\hline$\rho_{2}$ & & & & & $-0.474 * * *$ & 6.42 \\
\hline Log likelihood & -470.25 & & & & & \\
\hline Likelihood ratio of independence: $\chi^{2}(1)$ & & & $11.42 * *$ & & & \\
\hline
\end{tabular}

Note: $* * *$ and $* * *$ represent significance at $10 \%, 5 \%$ and $1 \%$ levels respectively Source: own processing

Table 2: Full information maximum likelihood estimates of endogenous switching regression model for adoption and impact of adoption on fish output. 


\begin{tabular}{|c|c|c|c|c|c|}
\hline & \multicolumn{2}{|c|}{ Selection } & \multicolumn{2}{|c|}{ Food Security } & \multirow{2}{*}{$\begin{array}{c}\text { Marginal } \\
\text { Effects }\end{array}$} \\
\hline & Coefficient & t-value & Coefficient & t-value & \\
\hline Constant & 9.920 & 4.14 & 4.918 & 1.89 & \\
\hline Risk management adoption & & & $0.029 * * *$ & 4.24 & 0.571 \\
\hline Age & $0.008 * * *$ & 5.77 & 0.009 & 0.24 & 0.083 \\
\hline Age2 & -0.041 & 1.10 & 0.172 & 1.11 & 0.012 \\
\hline Household size & $-0.043 * * *$ & 3.61 & $0.010 * * *$ & 4.43 & 0.038 \\
\hline Experience & 0.032 & 1.34 & $-0.241 * * *$ & 2.97 & 0.031 \\
\hline Marital status & 0.742 & 1.46 & -1.054 & 1.32 & 0.567 \\
\hline Education & $-0.539 * * *$ & 8.31 & $-0.131 * * *$ & 3.03 & 0.167 \\
\hline Non-farm income & $-1.081 * *$ & 2.10 & $-0.197 * * *$ & 4.52 & 0.188 \\
\hline Labour cost & -0.578 & 0.53 & -0.633 & 1.30 & 0.184 \\
\hline Credit constraint & $0.289 * * *$ & 2.72 & $0.619 * * *$ & 3.34 & 0.207 \\
\hline Pond system & $0.929 * * *$ & 8.23 & 0.694 & 0.81 & 0.067 \\
\hline Quantity of feed & $-0.270 * *$ & 1.87 & 0.225 & 0.64 & 0.131 \\
\hline Risk attitude & $-0.841 * * *$ & 7.36 & $-0.440 *$ & 1.94 & 0.345 \\
\hline Awareness & $-0.210 * * *$ & 5.95 & & & \\
\hline Credit residual & 0.081 & 0.73 & & & \\
\hline$\rho$ & $-0.735^{* * *}$ & 17.45 & & & \\
\hline Log likelihood & $-98.421 * * *$ & & & & \\
\hline
\end{tabular}

Note: $* * *$ and $* * *$ represent significance at $10 \%, 5 \%$ and $1 \%$ levels respectively

Source: own processing

Table 3: Full information maximum likelihood estimates of Recursive Bivariate Probit Model for adoption and impact of adoption on food security.

\section{Impact of determinants}

The estimates in the outcome equation in the columns for adopters and non-adopters in Table 2 generally show the impact of household and farm-level characteristics of women fish farmers on fish output. The impact estimates suggest that age of the respondent and level of education positively and significantly influenced fish outputs among adopters and non-adopters of risk management strategies. This implies that age and level of education tend to contribute to increasing fish output. The positive and significant relationship between age and fish output could be due to the sufficient knowledge that farmers have gathered through experience over the years of fish farming. This confirms the findings of Raufu et al. (2009) where it is reported that a positive and significant relationship existed between age of respondents and fish output. The positive and significant relationship between level of education and fish output reported in this study is in conformity with Ike and Chuks-Okonta (2014) who also reported a direct relationship between level of education and fish output.

Also, household size, non-farm income and quantity of feed are positively and significantly related to fish output among risk management strategies' adopters, indicating that these variables contribute to increasing fish output. The direct relationship between non-farm income and fish output shows the importance of non-farm income as it is used to cope with financial shocks. Ogundari and Akinbogun (2010) reported positive and significant relationship between quantity of feed and fish output, while Oluwasola and Ige (2015) recorded a positive and significant relationship between catfish profitability (as a proxy for fish output) and quantity of feed. Conversely, the negative and statistically significant coefficient of credit constraint and pond system indicate that being credit constrained and using earthen pond system would reduce fish output. This shows the importance of credit availability in fish production which supports Saqib et al. (2016) who stated that agricultural credit plays vital role as it has significant impacts on farmers' production, income and food security.

The impact estimates as shown in Table 3 under food security column show that there is a positive relationship between adoption of risk 
management strategies and food security status (headcount index), indicating that non-adoption of risk management strategies among women fish farmers tend to increase the probability of being food insecure. This is a clear indication that adoption of risk management strategies is very important when food security issue is being discussed. This confirms the statement of Kassie et al. (2015) which states that managing risk is an important aspect of reducing food insecurity, protecting livelihoods and opening up investment opportunities and income growth. Moreover, household size exhibits positive and significant relationship with food security (headcount index), which implies that increase in household size tends to increase the likelihood of being food insecure among women fish farmers. This could be linked to increased pressure on household resources (such as food) as household size increases, which may make such households to be food insecure. This is in line with the findings of Ibok et al. (2014) which explained that large size households tend to be more food insecure than small size households.

However, experience of women fish farmers, level of education and non-farm income negatively and significantly influenced food security (headcount index). This indicates that experience, level of education and non-farm income tend to increase the fish farmers' chance of being food secure. This may not be unconnected with the fact that experienced fish farmers are aware of some practices to put in place in order to realize optimum fish output which helps to be food secure. Ahmed et al. (2015) reported that food insecurity may arise as a result of low production and income caused by limited farming experience. The coefficients of credit constraint and risk attitude of women fish farmers had positive and negative significant relationship with food security (headcount index) respectively. The implication of this is that being credit constrained will likely lead to increase in the probability of being food insecure, while being risk seeking may bring about more chance of being food secure. These findings have further confirmed the findings of Saqib et al. (2016) who stated that agricultural credit plays vital role as it has significant impacts on farmers' food security.

The marginal effect estimates of the RBP specifications are interpreted as elasticities, which give the magnitude of the response of food security (headcount index) to any increase in each of the independent variables. For example, the marginal effect of household size with positive and significant estimate shows that additional household member is more likely to increase food insecurity by $3.8 \%$. The negative and statistically significant marginal effect estimate of level of education suggests that an additional year spent in school by women fish farmers is more likely to contribute to the household being food secure by $16.7 \%$. Also, the negative and significant marginal effect estimate of non-farm income implies that an additional amount of money in Naira by women fish farmers is more likely to increase the chance of being food secure by $18.8 \%$.

\section{Fish output and food security impacts}

Table 4 presents impact of adoption on fish output and food security from the ATT estimates of the ESR and RBP specifications. In order to examine the impact of risk management strategies' adoption on fish output and food security (headcount index), the average treatments effects (ATT) on the expected outcomes are estimated. It is worthy of note that ATT estimates account for other confounding factors which include selection bias resulting from potential differences between adopters and non-adopters. The results indicate that adoption significantly increases fish output and reduces food security headcount index. To be specific, the expected fish output from adopters is $1,172.2 \mathrm{~kg}$ compared with $753 \mathrm{~kg}$ from non-adopters. This difference represents increase in causal effect in fish output from adoption by $55.7 \%$. However, there is a negative impact of adoption on food security headcount from RBP estimates. The implication is that there is increase in the probability of reducing food insecurity from $87 \%$ from non-adopter to $58 \%$ from adopter. Kassie et al. (2015) explained that managing risk is an important aspect of reducing food insecurity, protecting livelihoods and opening up investment opportunities and income growth since it is clear that risk is an unavoidable part of economic and social activities in agriculture.

\begin{tabular}{|l|l|l|c|}
\hline Variable & Adopter & Non-adopter & ATT \\
\hline Output $(\mathrm{kg})$ & $1,172.2$ & 753.00 & $419.2 * * *$ \\
\hline Food security headcount & 0.58 & 0.87 & $-0.29 * * *$ \\
\hline
\end{tabular}

Note: $* * *$ represent significance at $1 \%$ levels

Source: own processing

Table 4: Impact of risk management.

\section{Conclusion}

This article examined the impact of risk management strategies adoption on fish output and food security among women aquaculture farmers. The study through the mean differences 
revealed that there are statistically significant differences in fish output and food security status between adopters and non-adopters of risk management strategies among women fish farmers. Despite the fact that these results can be interpreted as impacts, this study further analysed the data so as to observe the impacts while considering the effect of other factors, those that influenced adoption inclusive. This is necessary because of the failure of the mean differences to account for other factors. Endogenous Switching Regression model was used to estimate the adoption and impact of adoption on fish output, while Recursive Bivariate Probit model was employed to estimate the adoption impacts on food security (headcount index). It is indicated in this study that adoption of risk management strategies had positive and statistically significant influence on fish output but negative and statistically significant influence on food security (headcount). The empirical findings revealed that farmer's age, credit constraint, pond system, household size, education, non-farm income, quantity of feed and risk attitude had significant influence on adoption across the specifications. Also, household size, risk management strategies' adoption, experience, education, non-farm income, credit constraint and risk attitude had significant impact on food security among the respondents. Furthermore, the results showed that sample selection bias could have occurred while estimating the impact of risk management strategies' adoption on the outcomes without accounting for observable and unobservable factors. Women fish farmers who are non-adopters had lower output and higher food insecurity than a random individual from the sample. However, adopters had higher output and lower food insecurity than a random individual from the sample.

Based on the findings of this study, it is recommended that development agents should

\section{Corresponding authors}

Lawrence Olusola Oparinde, Ph.D

Department of Agricultural and Resource Economics

The Federal University of Technology, Akure, P.M.B. 704, Akure, Nigeria

Phone: +2348062317878,Email: saintlawrence8@yahoo.com; looparinde@futa.edu.ng

\section{References}

[1] Abdulai, A. N. (2016) "Impact of conservation agriculture technology on household welfare in Zambia", Agricultural Economics, Vol. 4, pp. 1-13. DOI 10.1111/AGEC.12269.

[2] Adepoju, A. O. and Adejare, K. A. (2013) "Food Insecurity Status of Rural Households during the Post-planting Season in Nigeria", Journal of Agriculture and Sustainability, Vol. 4, No. 1, pp. 6-35. ISSN 2201-4357. encourage women aquaculture farmers to adopt risk management strategies in order to have increased fish output and reduced food insecurity which can help in bridging the fish supply-demand gap and reducing their level of vulnerability. This is necessary since adoption of risk management strategies among women aquaculture farmers is capable of increasing fish output and reducing food insecurity. Also, since non-farm income has been reported to be one of the important factors that influenced adoption of risk management strategies, women fish farmers should be encouraged to involve in income diversification. This will help them to benefit from the importance of non-farm income in the risk management strategies' adoption process. The study revealed that non-credit constrained women fish farmers were reported to adopt risk management strategies more than their credit constrained counterparts. Therefore, reducing the problem of credit constraints will go a long way in increasing fish output through adoption of various risk management strategies. The study showed that increase in the level of education increased the likelihood of adopting risk management strategies. In view of this, policy measures that target increase in education investment should be put in place especially for women. Being aware about risk management strategies and risk seeking are likely to increase women fish farmers' chance of adopting risk management strategies. Therefore, proper attention should be given to women fish farmers' risk attitude and awareness about risk management when decisions are being made on risk management strategies in fish farming. Having seen the wonderful results coming from this study, it is recommended that further studies that expand the study to cover the whole country should be carried out. 
[3] Ahmed, F. F., Mohammed, M. and Abah, P. O. (2015) "An Analysis of Socio-Economic Characteristics and Food Security Situation among Semi-Urban Households: A Case Study of Biu and Bama Local Government Areas in Borno State, Nigeria”, Developing Country Studies, Vol. 5, No. 6, pp. 59-68. E-ISSN 2225-0565.

[4] Ahsan, D. A. and Roth, E. (2010) "Farmers' Perceived Risks and Risk Management Strategies in an Emerging Mussel Aquaculture Industry in Denmark", Marine Resource Economics, Vol. 25, pp. 309-323. ISSN 0738-1360. DOI 10.5950/0738-1360-25.3.309.

[5] Amare, M., Asfaw, S. and Shiferaw, B. (2012) "Welfare impacts of maize-pigeon pea intensification in Tanzania", Agricultural Economics, Vol. 43, No.1, pp. 27-43. E-ISSN 1574-0862. DOI 10.1111/J.1574-0862.2011.00563.X.

[6] Asfaw, S., Shiferaw, B., Simtowe, F. and Lipper, L. (2012) "Impact of modern agricultural technologies on smallholder welfare: Evidence from Tanzania and Ethiopia”, Food Policy. Vol. 37 , No. 3, pp. 283-295. ISSN 0306-9192. DOI 10.1016/J.FOODPOL.2012.02.013.

[7] Awotide, B. A., Diagne, A. and Awoyemi, T. T. (2013) "Agricultural Technology Adoption, Market Participation and Rural Farming Households' Welfare in Nigeria", Invited paper presented at the $4^{\text {th }}$ International Conference of the African Association of Agricultural Economists, September 22-25, 2013, Hammamet, Tunisia. [Online]. Available: http://ageconsearch.umn.edu/record/160428. [Accessed: 25 Aug. 2018].

[8] Blundell, R. W. and Smith, R. J. (1989) "Estimation in a class of simultaneous equation limited dependent variable models", The Review of Economic Studies, Vol. 56, No.1, pp. 37-57. E-ISSN 1467-937X, ISSN 0034-6527. DOI 10.2307/2297748.

[9] Bostock, J., McAndrew, B., Richards, R., Jauncey, K., Telfer, T., Lorenzen, K., Little, D., Ross, L., Handisyde, N., Gatward, I. and Corner, R. (2010) "Aquaculture: global status and trends", Philosophical Transactions of the Royal Society B: Biological Sciences, Vol. 365, No. 1554, pp. 2897-2912. DOI 10.1098/RSTB.2010.0170.

[10] Deressa, T. T., Ringler, C., and Hassan, R. M. (2010) "Factors Affecting the Choices of Coping Strategies for Climate Extremes. The Case of Farmers in the Nile Basin of Ethiopia", IFPRI Discussion Paper. [Online]. Available: http://cdm15738.contentdm.oclc.org/utils/getfile/collection/ p15738coll2/id/5198/filename/5199.pdf. [Accessed: 22 Aug. 2018].

[11] Food and Agriculture Organization (FAO) (2003) "Proceedings Measurement and Assessment of Food Deprivation and Under-nutrition”, International Scientific Symposium, Rome, June 26-28. [Online]. Available: http://www.fivims.net/EN/ISS.htm. [Accessed: 22 Aug. 2018].

[12] Food and Agriculture Organization (FAO), (2013) "FAO Country Programming Framework (CPF) Federal Republic of Nigeria", pp. 1-41. [Online]. Available: www.fao.org/3/a-au053e.pdf. [Accessed: 22 Aug. 2018].

[13] Food and Agriculture Organization (FAO) (2016) "Climate change and food security: risks and responses". Food and Agriculture Organization of the United Nations, Rome. ISBN/ISSN 9789251089989.

[14] Forum for Agricultural Risk Management Development (FARMD) (2017) "Risk Management in Aquaculture", [Online]. Available: http://www.agriskmanagementforum.org/fstory/riskmanagement-aquaculture). [Accessed: 20 Aug. 2018].

[15] Garcia, S. M. and Rosenberg, A. A. (2010) "Food security and marine capture fisheries: characteristics, trends, drivers and future perspectives", Philosophical Transactions of the Royal Society B: Biological Sciences, Vol. 365, No. 1554, pp. 2869-2880. DOI 10.1098/RSTB.2010.0171.

[16] Harwood, J., Heifner, R., Coble, K., Perry, J. and Somwaru, A. (1999) “Managing Risk in Farming: Concepts, Research, and Analysis", Economics Research Service, U.S. Department of Agriculture: Washington D.C. [Online]. Available: https://www.ers.usda.gov/publications/pubdetails/?pubid=40971. [Accessed: 20 Aug. 2018]. 
[17] Hecht, T. (2006) "Regional review on aquaculture development - Sub-Saharan Africa 2005", FAO Fisheries circular, No. 1017/4, Rome, ISSN 0429-9329.

[18] Heckman, J. J. (1979) "Sample selection bias as a specification error", Econometrica. Vol. 47, pp. 153-61. E-ISSN 14680262, ISSN 00129682. DOI 10.2307/1912352.

[19] HLPE (2014) "Sustainable fisheries and aquaculture for food security and nutrition. A report by the High Level Panel of Experts on Food Security and Nutrition of the Committee on World Food Security", Rome. [Online]. Available: http://foodsecurityindex.eiu.com/Country/Details\#Nigeria. [Accessed: 8 Aug. 2018].

[20] Hurley, T. M. (2010) "A review of agricultural production risk in the developing world", Harvest Choice Working Paper. [Online]. Available: Available on www.harvestchoice.org. [Accessed: 5 Aug. 2018].

[21] Ibok, O. W., Bassey, N. E., Atairet, E. A. and Obot , O. J. (2014) "Food Security Determinants among Urban Food Crop Farming Households in Cross River State, Nigeria", Asian Journal of Agricultural Extension, Economics \& Sociology, Vol 3, No. 1, pp. 76-90. ISSN: 2320-7027. DOI 10.9734/AJAEES/2014/6560.

[22] Ike, P. C. and Chuks-Okonta, V. A. (2014) "Determinants of Output and Profitability of Aquaculture Fish Farming in Burutu and Warri South West Local Government Areas of Delta State, Nigeria", Journal of Biology, Agriculture and Healthcare, Vol. 4, No.28, pp. 102-108. ISSN 2225-093X.

[23] Joshi, O., Grebner, D. L., Munn, I. A. and Grala R. K. (2015) "Issues Concerning Landowner Management Plan Adoption Decisions: A Recursive Bivariate Probit Approach", International Journal of Forestry Research, Vol. 2015, pp. 1-8. ISSN 1687-9376, ISSN 1687-9368. DOI 10.1155/2015/926303.

[24] Kassie, M., Teklewold, H., Marenya, P., Jaleta, M. and Erenstein, O. (2015) "Production Risks and Food Security under Alternative Technology Choices in Malawi: Application of a Multinomial Endogenous Switching Regression”, Journal of Agricultural Economics, Vol. 66, No. 3, pp. 640-659. E-ISSN 1477-9552. DOI 10.1111/1477-9552.12099.

[25] Kuntashula, E., Chabala, L. M. and Mulenga, B. P. (2014) "Impact of minimum tillage and crop rotation as climate change adaptation strategies on farmer welfare in smallholder farming systems of Zambia”, Journal of Sustainable Development, Vol. 7, No. 4, pp. 95-110. ISSN 1913-9071. DOI $10.5539 /$ jsd.v7n4p95.

[26] Lokshin, M. and Sajaia Z. (2004) "Maximum likelihood estimation of endogenous switching regression models", Stata Journal, Vol. 4, No.3, pp. 282-289.

[27] Maddala, G. S. (1983) "Limited-Dependent and Qualitative Variables in Econometrics", Cambridge University Press, New York. ISBN 9780511810176, DOI 10.1017/CBO9780511810176.

[28] Marra, G. and Radice, R. (2011) "Estimation of a semiparametric recursive bivariate probit model in the presence of endogeneity", Canadian Journal Statistics, Vol. 39, pp. 259-279. E-ISSN 1708-945X. DOI 10.1002/cjs.10100.

[29] National Bureau of Statistics (NBS) (2011) “Annual Abstract of Statistics". [Online]. Available: www.nigerianstat.gov.ng. [Accessed: 20 Sept. 2018].

[30] Nkala, P., Mango, N. and Zikhali, P. (2011) "Conservation Agriculture and Livelihoods of Smallholder Farmers in Central Moyambique", Journal of Sustainable Agriculture, Vol. 35 , No. 7, pp. 757-779. E-ISSN 2168-3573, ISSN 2168-3565. DOI 10.1080/10440046.2011.606492.

[31] Ogundari, K. and Akinbogun, O. O. (2010) "Modeling Technical Efficiency with Production Risk: A Study of Fish Farms in Nigeria", Marine Resource Economics, Vol. 25, No. 3, pp. 295-308. ISSN 0738-1360. DOI 10.5950/0738-1360-25.3.295.

[32] Oladimeji, Y. U. (2017) "Trend in Fish Production Parameters in Nigeria and its Total Estimated Demand: Empirical Evidence from Fish Production", Journal of Animal Production and Resources, Vol. 29, No. 1, pp. 410-418. ISSN 0189-0514. 
[33] Olawuyi, S. and Olawuyi, T. (2015) "Risk Management Strategies Adoption of Farming Households in Kwara State of Nigeria: A Pragmatic Approach", Proceedings of International Academic Conferences 2704628, International Institute of Social and Economic Sciences.

[34] Oluwasola, O. and Ige, A. O. (2015) "Factors Determining the Profitability of Catfish Production in Ibadan, Oyo State, Nigeria", Sustainable Agriculture Research, Vol. 4, No. 4, pp. 57-65. E-ISSN 1927-0518, ISSN 1927-050X. DOI 10.5539/SAR.V4N4P57.

[35] Ondo State Government (2016) “Background information about Ondo State”, [Online]. Available: www.ondostate.gov.ng. [Accessed: 12 Sept. 2018].

[36] Oseni, J. O. (2010) "Effects of deregulation policy on cocoa marketing in Ondo State, Nigeria", Ph.D. Dissertation., Department of Agricultural Economics and Extension, Federal University of Technology, Akure, Nigeria.

[37] Raufu, M. O., Adepoju, A. A., Salau, A. S. and Adebiyi, O. A. (2009) "Determinants of yield Performance in Small Scale Fish Farming in Alimosho Local Government Area of Lagos State". International Journal of Agricultural Economics \& Rural Development, Vol. 2, No. 1, pp. 9-14. ISSN-L 1596-9916.

[38] Saqib, S., Ahmad, M. M., Panezai, S. and Ali, U. (2016) "Factors influencing farmers' adoption of agricultural credit as a risk management strategy: The case of Pakistan", International Journal of Disaster Risk Reduction, Vol. 17, No. C, pp. 67-76. ISSN 2212-4209. DOI 10.1016/j.ijdrr.2016.03.008.

[39] Sethi, S. A. (2010) "Risk management for fisheries”, Fish and Fisheries, Vol.11, NO. 4, pp. 341-365. E-ISSN 1467-2979. DOI 10.1111/J.1467-2979.2010.00363.X.

[40] The Economist Group (2017) “Global Food Security Index". [Online]. Available: http://foodsecurityindex.eiu.com/Country/Details\#Nigeria. [Accessed: 15 Sept. 2018].

[41] Tveterås, R. (1999) "Production risk and productivity growth: Some findings for Norwegian salmon aquaculture", Journal of Productivity Analysis, Vol. 12, No. 2, pp. 161-179. ISSN 1573-0441. DOI 10.1023/A:1007863314751.

[42] Ullah, R. and Shivakoti, G. P. (2014) "Adoption of on-farm and off-farm diversification to manage agricultural risks: Are these decisions correlated?”, Outlook on Agriculture, Vol. 43, No. 4, pp. 265-271. DOI 10.5367/OA.2014.0188.

[43] Ullah, R., Jourdain, D., Shivakoti, G. P. and Dhakal, S. (2015) "Managing Catastrophic Risks in Agriculture: Simultaneous Adoption of Diversification and Precautionary Savings", International Journal of Disaster Risk Reduction, Vol. 12, pp. 268-277. ISSN 2212-4209. DOI 10.1016/J.IJDRR.2015.02.001.

[44] Wooldridge, J. M. (2010) "Econometric Analysis of Cross Section and Panel Data", Cambridge, Massachusetts, MIT Press. ISBN 9780262232197.

[45] World Food Summit (1996) "Rome Declaration on World Food Security", Rome, FAO. [Online]. Available: http://www.fao.org/docrep/003/w3613e/w3613e00.htm. [Accessed: 21 Aug. 2018]. 